ORIGINAL ARTICLE

\title{
Interstitial cells of Cajal, enteric nerves, and glial cells in colonic diverticular disease
}

\author{
G Bassotti, E Battaglia, G Bellone, L Dughera, S Fisogni, C Zambelli, A Morelli, P Mioli, \\ G Emanuelli, V Villanacci
}

J Clin Pathol 2005;58:973-977. doi: 10.1136/jcp.2005.026112

See end of article for authors' affiliations .....................

Correspondence to: Dr G Bassotti, Clinica di Gastroenterologia ed Epatologia, Via Enrico Dal Pozzo, Padiglione W, 06100 Perugia, Italy; gabassot@tin.it

Accepted for publication 1 February 2005
Background: Colonic diverticular disease (diverticulosis) is a common disorder in Western countries. Although its pathogenesis is probably multifactorial, motor abnormalities of the large bowel are thought to play an important role. However, little is known about the basic mechanism that may underlie abnormal colon motility in diverticulosis.

Aims: To investigate the interstitial cells of Cajal (the gut pacemaker cells), together with myenteric and submucosal ganglion and glial cells, in patients with diverticulosis.

Patients: Full thickness colonic samples were obtained from 39 patients undergoing surgery for diverticulosis. Specimens from tumour free areas of the colon in 10 age matched subjects undergoing surgery for colorectal cancer served as controls.

Methods: Interstitial cells of Cajal were assessed using anti-Kit antibodies; submucosal and myenteric plexus neurones and glial cells were assessed by means of anti-PGP 9.5 and anti-S-100 monoclonal antibodies, respectively.

Results: Patients with diverticulosis had normal numbers of myenteric and submucosal plexus neurones compared with controls ( $p=0.103$ and $p=0.516$, respectively). All subtypes of interstitial cells of Cajal were significantly ( $p=0.0003$ ) reduced compared with controls, as were glial cells $(p=0.0041)$.

Conclusions: Interstitial cells of Cajal and glial cells are decreased in colonic diverticular disease, whereas enteric neurones appear to be normally represented. This finding might explain some of the large bowel motor abnormalities reported to occur in this condition.
C onic diverticular disease (diverticulosis) is a frequen gastrointestinal disorder in developed countries'; it is characterised by the development of pseudo-diverticula-protrusions of the mucosa and submucosa through the muscular wall-occurring in weaker areas of the wall where blood vessels penetrate. ${ }^{2}$ Several aetiological cofactors have been implicated in the pathogenesis of this disease. Among these, abnormal colonic motility is thought to be an important mechanism ${ }^{3-5}$; patients with diverticulosis display abnormal motility and colonic propulsive activity, particularly in the segments bearing diverticula. ${ }^{6-8}$

\section{"The interstitial cell of Cajal network plays a pivotal role in the generation of electrical activity and motor coordination along the gastrointestinal tract"}

It is unfortunate that neurophysiopathological data related to this condition are extremely scarce; an early investigation of the myenteric plexus in diverticulosis, using conventional and silver stains, found no morphological abnormalities. ${ }^{9}$ No data are yet available on the pathophysiological mechanisms leading to abnormal colonic motor activity in diverticulosis; in particular, the role of the interstitial cells of Cajal (ICC) is unknown. These cells are crucial for the generation and propagation of pacemaker activity and for the reception of regulatory inputs from the enteric nervous system ${ }^{10}$; the ICC network plays a pivotal role in the generation of electrical activity and motor coordination along the gastrointestinal tract. ${ }^{11}$ In the human colon, three populations of ICC have been identified ${ }^{12}{ }^{13}$ : IC-SM, along the submucosal surface of the circular muscle bundle; IC-MY, within the intermuscular space between circular and longitudinal muscle layers (myenteric region, which displays the highest yield of ICC in normal tissue $\left.{ }^{14-16}\right)$; and IC-IM, within the muscle fibres of the circular and longitudinal muscle layers. From the available evidence, it seems that the chief function of ICSM and IC-MY is to generate slow wave activity, whereas ICIM mediate inputs from the enteric nervous system. ${ }^{11}$

Owing to the fact that ICC express Kit, ${ }^{17}$ immunohistochemical analysis using anti-Kit antibodies has proved to be an efficient tool for identifying these cells in a variety of species, including humans. ${ }^{18-20}$

Our present study evaluated the various ICC subtypes and neuronal marker expression in colonic specimens taken from patients with diverticulosis. Our working hypothesis was that these patients might have ICC and/or neuronal abnormalities responsible for the altered motility of the large bowel found in this condition.

\section{METHODS AND MATERIALS \\ Patients}

Colon specimens were obtained from 39 patients ( 17 men, 22 women; age range, 49-78 years) undergoing elective left hemicolectomy for diverticular disease (35 cases) or emergency surgery for acute diverticulitis with pericolic abscess (four cases) in the period January 1999 to January 2004. None of the patients had concomitant tumours, bowel obstruction, or other diseases of the colon. The studies were carried out in accordance with local ethical guidelines, following the recommendations of the Declaration of Helsinki (Edinburgh revision, 2000).

Abbreviations: ICC, interstitial cells of Cajal; IC-IM, muscle fibre interstitial cells of Cajal; IC-MY, myenteric region interstitial cells of Cajal; IC-SM, submucosal interstitial cells of Cajal; PGP 9.5, protein gene product 9.5 

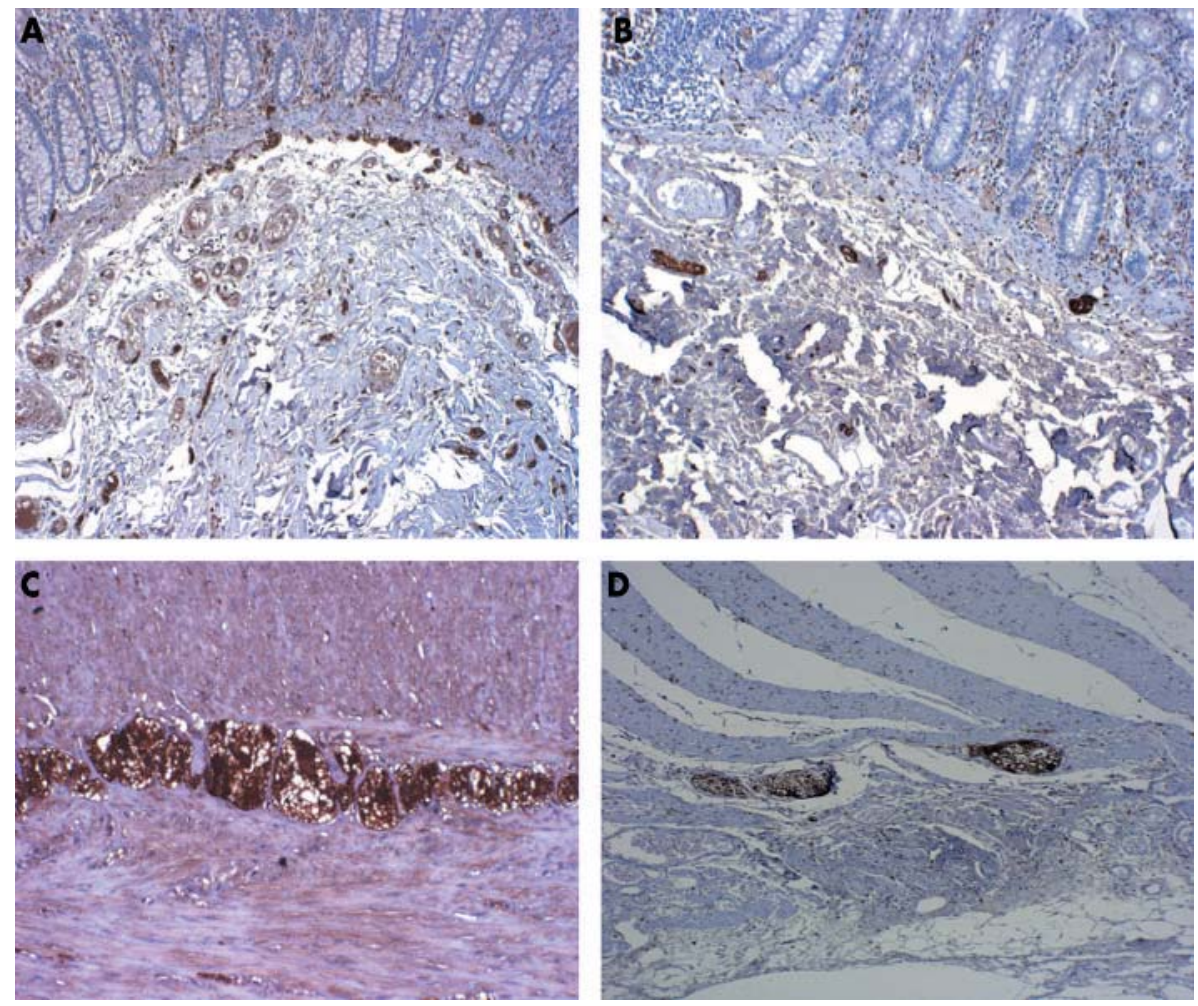

Figure 1 Expression of PGP 9.5 in the submucosal and myenteric plexus of controls ( $A$ and $C$, respectively) and patients ( $B$ and $D$, respectively). Original magnification, $\times 20(A, B)$ and $\times 40(C, D)$.

\section{Controls}

We used 10 specimens from age and sex matched subjects undergoing left hemicolectomy for non-obstructing colorectal cancer as controls. The control specimens were taken at least $5 \mathrm{~cm}$ from the resection margin in tumour free areas.

\section{Methods}

After removal, the surgical specimens were immediately fixed in $10 \%$ neutral buffered formalin for 24 hours, then 12 to 20 full thickness samples were taken from portions bearing diverticula and from those that were macroscopically normal. For conventional histology, $5 \mu \mathrm{m}$ thick paraffin wax embedded sections were stained with haematoxylin and eosin, periodic acid Schiff, and trichrome stain.

\section{Immunohistochemistry}

At least 10 samples (five from diverticular and five from macroscopically normal portions) for each patient were processed for immunohistochemistry. To evaluate the enteric nervous system, ${ }^{21}$ we investigated PGP 9.5 (protein gene product 9.5), a cytoplasmic protein that acts as a marker of general neural tissue, ${ }^{22}{ }^{23}$ and the glial marker protein S-100. ${ }^{24}$ Ganglion cells were assessed with a monoclonal anti-PGP 9.5 antibody (IgG2a; 1/100 dilution; Biomeda, Foster City, California, USA); Schwann cells, intragangliar glial cells close to ICC, and myenteric ganglia were assessed with a specific monoclonal antibody (anti-S-100; 1/50 dilution; Dako, Carpinteria, California, USA). S100 immunostaining highlights ganglion cells as prominent negatively stained cells surrounded by positive Schwann/glial cells.

The expression of Kit (CDI17) was assessed using a rabbit polyclonal antibody (IgG; dilution 1/50; Dako) specific for ICC. In brief, consecutive formalin fixed, paraffin wax embedded sections were dewaxed and rehydrated through a decreasing alcohol series up to distilled water. Sections were then subjected to heat induced epitope retrieval by immersion in a heat resistant container filled with citrate buffer solution ( $\mathrm{pH} 6.0$ ), placed in a pressure cooker, and microwaved for 20 minutes. Endogenous peroxidase activity was blocked by incubation with a $3 \%$ solution of $\mathrm{H}_{2} \mathrm{O}_{2}$ for five minutes. Kit immunostaining was carried out using a peroxidase based visualisation kit (Dako EnVision ${ }^{\mathrm{TM}}$ ), according to the manufacturer's recommendations. PGP 9.5 and S-100 immunostaining was carried out by means of a peroxidase based visualisation kit (Dako LSAB ${ }^{\circledR}$ ), according to the manufacturer's recommendations. Diaminobenzidine tetrahydrochloride was used as the chromogen. The slides were then counterstained with Mayer's haematoxylin for five seconds, dehydrated, and mounted in Clarion (Biomeda). To account for non-specific staining, peptides that blocked polyclonal antibody binding (passage with normal goat serum) were used, or sections were incubated in the absence of primary antibody. In these cases, no immunostaining was detected.

Kit positive mast cells served as an internal positive control. Not only nucleated cells but also Kit positive labelled elongated structures in the diverticular sacs of patients were compared with tumour free areas in the controls.

For PGP 9.5 and S100 staining, both the submucosal and the myenteric plexuses were assessed using optical microscopy at $\times 20$ magnification (Olympus BX 40, Tokyo, Japan). For each patient, the number of immunopositive cells was calculated and expressed as the mean number of cells in 10 well stained and well oriented microscopic fields for each region of interest, with each field having an area of $0.785 \mathrm{~mm}^{2}$. The density of ICC was graded, according to a previously described method, ${ }^{14}$ after the evaluation of 10 well stained and well oriented high power fields. The longitudinal muscle layer, intermuscular layer, and circular muscle layer were each assessed in 10 different fields. 


\section{Statistical analysis}

The Kolmogorov-Smirnov test for normality was applied and showed that the data were normally distributed. Data from controls and patients were thus compared by means of the Student's $t$ test for unpaired data. Values of $\mathrm{p}<0.05$ were chosen for rejection of the null hypothesis.

\section{RESULTS}

\section{Conventional histology}

In both groups, the mucosa, submucosa, smooth muscle, and nerve plexus architecture appeared normal on haematoxylin and eosin, trichrome, and periodic acid Schiff staining. In the four cases in which diverticulitis was acute, an inflammatory infiltrate cytologically composed of neutrophils, lymphocytes, macrophages, and occasional giant plurinucleated cells was seen, localised in and around the boundaries of the affected diverticular sacs. Apart from these cases, and the presence of occasional neutrophils, plasma cells, and lymphocytes mainly within the luminal aspects of the lamina propria in both groups, no acute inflammatory cells (or intranuclear or viral inclusions) were seen in or around muscular or nervous structures (particularly at the myenteric plexus level).

\section{Immunohistochemistry}

The expression of PGP 9.5 was not significantly different between patients with diverticulosis and controls, either in the myenteric plexus (mean, 50 (SD, 17) v 60 (17) cells; $\mathrm{p}=0.103$ ) or in the submucosal plexus (mean, 41.2 (SD, 15) $v 44.5$ (11) cells; $p=0.516$; fig 1 ). The number of $S-100$ positive cells was significantly lower in patients in both the myenteric plexus (mean, 171 (SD, 40) v 214.4 (33.3) cells; $\mathrm{p}=0.0041$ ) and the submucosal plexus (mean, $78.3(27.4) \mathrm{v}$ 127 (47) cells, $p=0.0004$; fig 2). There was a significant decrease at each anatomical region in patients with diverticulosis for all three subclasses of ICC evaluated (IC-SM: mean, $7.6(4.4) v 29$ (8) cells, $\mathrm{p}=0.0001$; IC-MY: mean, $131.3(\mathrm{SD}, 43) \vee 214.2(84)$ cells, $\mathrm{p}=0.0003$; IC-IM: mean, $10(7) \vee 37$ (12) cells, $\mathrm{p}=0.0001$; fig 3 ). No differences with regard to $\mathrm{S}-100$ and Kit positive cells were found between the four patients with acute diverticulitis and the other patients with diverticulosis, or between diverticular and non-diverticular areas.

Scattered Kit positive cells (identified as mast cells and used as internal controls) were seen in the patients' mucosa, and had a similar distribution to that seen in the control tissue. No alterations in size or shape were seen in the three ICC subpopulations.
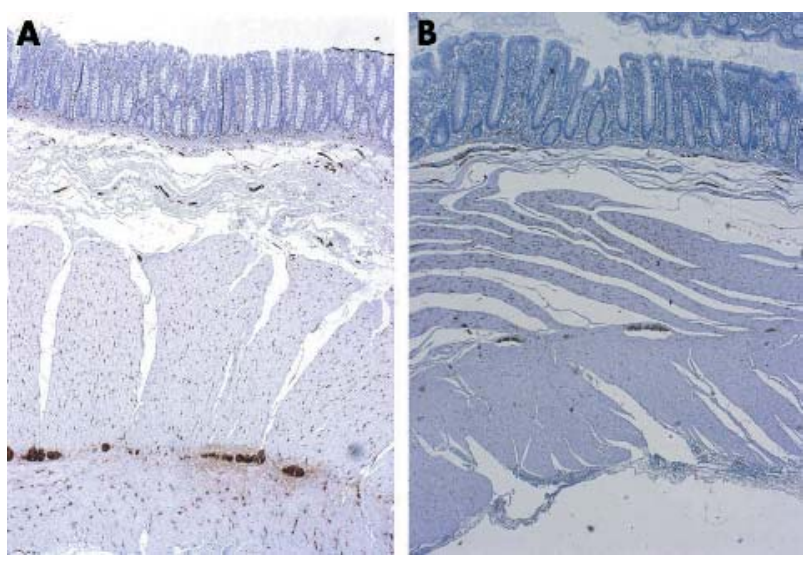

Figure 2 Expression of S-100 in the submucosal and myenteric plexus in (A) controls and (B) patients. Original magnification, $\times 20$.

\section{DISCUSSION}

The main finding of our study was that patients with colonic diverticulosis have significantly reduced numbers of colonic ICC and enteric glial cells compared with controls. To our knowledge, this is the first study to have revealed such abnormalities. We focused our attention on ICC because an increasing amount of recent evidence indicates that this cell population plays a pivotal role in the regulation of intestinal motor function. ${ }^{112}$ This is supported by the fact that, in addition to functioning as pacemaker cells that generate slow waves, ICC mediate neurotransmission from enteric motor neurones. ${ }^{25}$ In fact, these cells are an integral part of the neuromuscular junction of the colon, and may be the primary site of innervation; neural regulation of the musculature may also occur via the ICC. ${ }^{26}$

\section{"The reduction of interstitial cell of Cajal function might be responsible for the significant decrease in rhythmic colonic contractile patterns that we recently described in patients with diverticulosis"}

The role of ICC as intestinal pacemakers has been clearly established in experimental animal models, which have shown that a lack of ICC networks leads to the absence of slow waves and is accompanied by delayed or absent intestinal motility. ${ }^{27}{ }^{28}$ In the upper gastrointestinal tract a lack or paucity of ICC has been found in diseases associated with gastric and small bowel motility (diabetic gastroparesis, chronic intestinal pseudo-obstruction, etc). ${ }^{29}{ }^{30}$ Data on human colonic ICC are still scarce, especially in pathological conditions, and chiefly limited to congenital diseases and slow transit constipation. ${ }^{151631}$ We decided to study diverticular disease because it is a disorder with frequent and measurable alterations of colonic motility. ${ }^{732}$ We found that these patients consistently had a significant reduction of all subpopulations of ICC and of enteric glial cells, whereas the enteric neuronal population appeared to be normal. These alterations might explain the colonic motor abnormalities documented in patients with diverticulosis (increased overall motility, abnormal response to eating, retropropagation of mass movements, etc). We are presently unable to explain why decreased numbers of colonic ICC and S-100 positive cells and structures should be associated with motor abnormalities. It is possible that a reduction or loss of ICC function decreases or eliminates colonic electrical slow wave activity, thereby decreasing the contractile response and resulting in delayed transit. For example, the reduction of ICC function might be responsible for the significant decrease in rhythmic colonic contractile patterns that we recently described in patients with diverticulosis ${ }^{33}$; in an experimental animal model these patterns appear to be driven by ICC. ${ }^{34}$

Moreover, because enteric glial cells are thought to function as intermediaries in enteric neurotransmission, ${ }^{35}$ their decrease might further weaken the already precarious neuroenteric balance described thus far.

Although ICC drive spontaneous rhythmic motility in the gut, the enteric nervous system may also play a role. ${ }^{36}$ This is particularly true in diverticulosis, where loss of smooth muscle choline acetyltransferase activity, upregulation of M3 receptors, and increased in vitro sensitivity of the smooth muscle to exogenous acetylcholine have been documented, ${ }^{37} 38$ suggesting that cholinergic denervation hypersensitivity may occur in this condition. The association of such alterations with a decrease in ICC might contribute to the motor abnormalities described in diverticulosis.

The evidence is clearly insufficient to determine whether loss of ICC in diverticulosis is a primary event or is secondary to another lesion or to the rearrangement that occurs when 

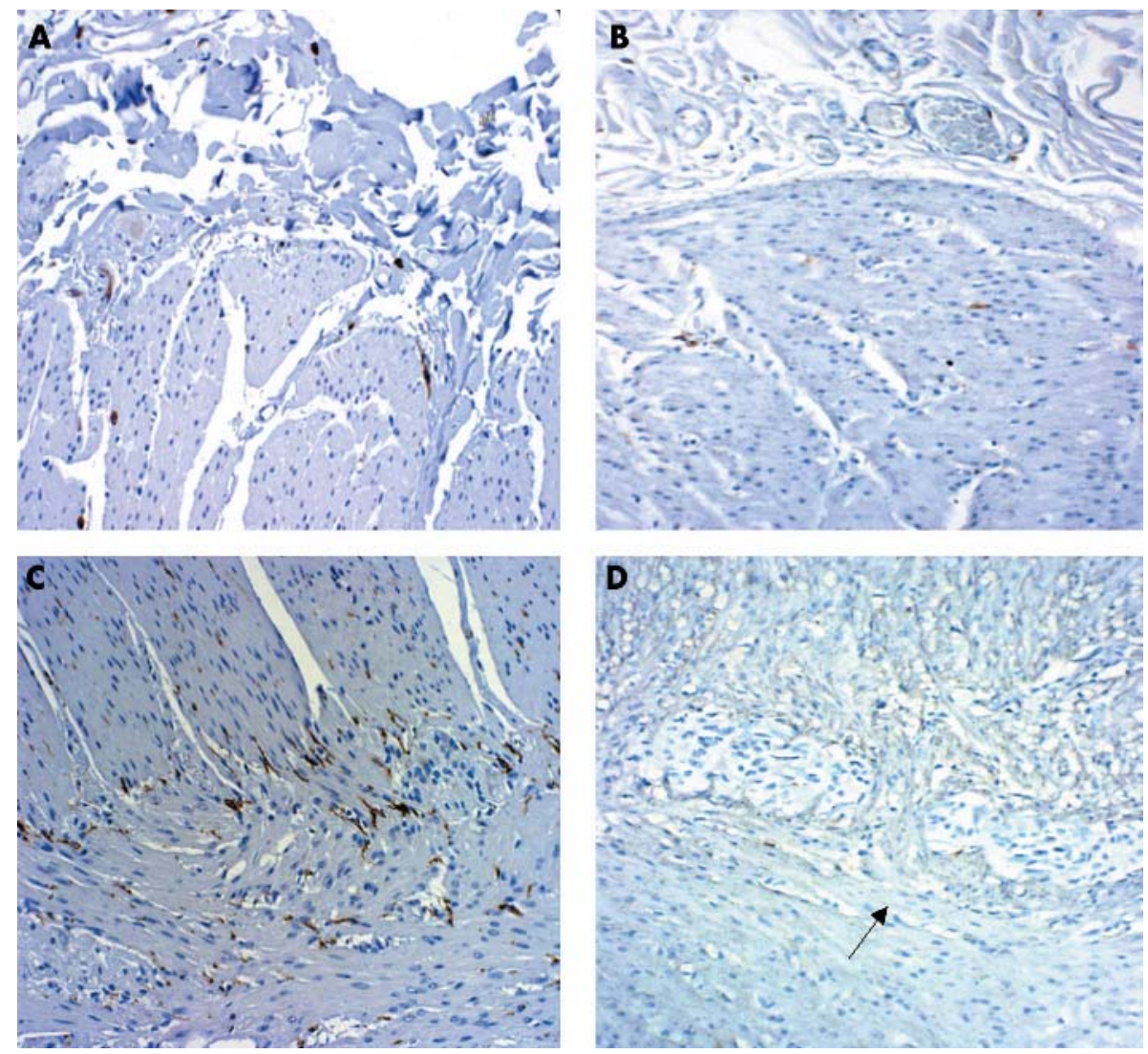

Figure 3 Expression of Kit in the submucosal and myenteric plexus of controls ( $A$ and $C$, respectively) and patients ( $B$ and $D$, respectively). Original magnification, $\times 10$.

changes take place in the colonic wall. A mechanical factor (for instance the push leading to diverticula formation with compression/atrophy of surrounding structures, including ICC and nerve structures) cannot be ruled out.

Similar considerations on whether these changes are primary or secondary to (still) unknown factors may be applied to other pathological conditions of the colon in which a decrease of ICC has been demonstrated, such as slow transit constipation ${ }^{15} 16$ and intestinal pseudo-obstruction. In fact, in about one third of cases of intestinal pseudoobstruction limited to the colon a consistent reduction of ICC, similar to that found here in patients with diverticulosis, has recently been described. ${ }^{39}$

However, increasing evidence from experimental animal models and reports in human subjects suggest that the ICC may play an important role in the pathophysiology of gastrointestinal motor abnormalities; these data shed new light on the mechanisms underlying diverticulosis and provide new directions for further studies on motor

\section{Take home messages}

- Numbers of interstitial cells of Cajal and glial cells were decreased in colonic diverticular disease, whereas the numbers of enteric neurones appeared to be normal

- These findings might explain some of the large bowel motor abnormalities known to occur in diverticulosis

- Further studies are needed on motor abnormalities in the gastrointestinal tract abnormalities in the gastrointestinal tract, with possible specific targeting of future therapeutic approaches. ${ }^{40}$

\section{Authors' affiliations}

G Bassotti, A Morelli, Gastroenterology and Hepatology Section, Department of Clinical and Experimental Medicine, University of Perugia, 06100 Perugia, Italy

E Battaglia, L Dughera, Departments of Gastroenterology and Clinical Nutrition, San Giovanni Battista Hospital, 10020 Turin, Italy

P Mioli, Emergency Surgical Unit, San Giovanni Battista Hospital G Bellone, G Emanuelli, Department of Clinical Pathophysiology, University of Turin, 10020 Turin, Italy

S Fisogni, C Zambelli, V Villanacci, Second Pathology Department, Spedali Civili, 25100 Brescia, Italy

\section{REFERENCES}

1 Delvaux M. Diverticular disease of the colon in Europe: epidemiology, impact on citizen health and prevention. Aliment Pharmacol Ther 2003;18(suppl 3):71-4

2 West AB, Losada M. The pathology of diverticulosis coli. J Clin Gastroenterol 2004;38(suppl 5):S11-16.

3 Simpson J, Scholefield JH, Spiller RC. Pathogenesis of colonic diverticula. BrJ Surg 2002;89:546-54.

4 Bassotti G, Chistolini F, Morelli A. Pathophysiological aspects of diverticular disease of colon and role of large bowel motility. World J Gastroenterol 2003:9:2140-2.

5 Stollman N, Raskin JB. Diverticular disease of the colon. Lancet 2004;363:631-9.

6 Weinreich J, Moller SH, Andersen D. Colonic haustral pattern in relation to pressure activity and presence of diverticula. Scand J Gastroenterol 1977; 12:857-64

7 Trotman IF, Misiewicz JJ. Sigmoid motility in diverticular disease and the irritable bowel syndrome. Gut 1988;29:218-22

8 Bassotti G, Battaglia E, Spinozzi F, et al. Twenty-four hour recordings of colonic motility in patients with diverticular disease. Evidence for abnormal motility and propulsive activity. Dis Colon Rectum 2001;44:1814-20. 
9 Vuong NP, Sezeur A, Balaton A, et al. Myenteric plexuses and colonic diverticulosis: results of a histological study. Gastroenterol Clin Biol 1985;9:434-6.

10 Ward SM, Sanders KM. Physiology and pathophysiology of the interstitial cell of Cajal: from bench to bedside. I. Functional development and plasticity of interstitial cells of Cajal networks. Am J Physiol 2001;281:G602-11.

11 Sanders KM, Ordog T, Koh SD, et al. Development and plasticity of interstitial cells of Cajal. Neurogastroenterol Motil 1999;11:311-38.

12 Sanders KM. A case for interstitial cells of Cajal as pacemakers and mediators of neurotransmission in the gastrointestinal tract. Gastroenterology 1996; 111:492-515

13 Ward SM, Sanders KM, Hirst GD. Role of interstitial cells of Cajal in neural control of gastrointestinal smooth muscles. Neurogastroenterol Motil 2004; 16(suppl 1):112-17.

14 Hagger R, Gharaie S, Finlayson C, et al. Regional and transmural density of interstitial cells of Cajal in human colon and rectum. Am J Physiol 1998;38:G1309-16.

15 Lyford GL, He C-L, Soffer E, et al. Pan-colonic decrease in interstitial cells of Cajal in patients with slow transit constipation. Gut 2002;51:496-501.

16 Tong WD, Liu BH, Zhang LY, et al. Decreased interstitial cells of Cajal in the sigmoid colon of patients with slow transit constipation. Int J Colorectal Dis 2004; 19:467-73.

17 Williams DE, Eisenman J, Baird A, et al. Identification of a ligand for the c-kit proto-oncogene. Cell 1990;63:167-74.

18 Yamataka A, Kato Y, Tibboel D, et al. A lack of intestinal pacemaker (c-kit) in aganglionic bowel of patients with Hirschsprung's disease. J Pediatr Surg 1995;30:441-4.

19 Horisawa M, Watanabe Y, Torihashi S. Distribution of c-Kit immunopositive cells in normal human colon and in Hirschsprung's disease. J Pediatr Surg 1998;33:1209-14

20 Nemeth L, Puri P. Three-dimensional morphology of c-Kit-positive cellular network and nitrergic innervation in the human gut. Arch Pathol Lab Med 2001;125:899-904.

21 Krammer HJ, Karahan ST, Sigge W, et al. Immunohistochemistry of markers of the enteric nervous system in whole-mount preparations of the human colon. Eur J Pediatr Surg 1994;4:274-8.

22 Lundberg LM, Alm P, Wharton J, et al. Protein gene product 9.5 (PGP 9. 5): a new neuronal marker visualizing the whole uterine innervation and pregnancy-induced and developmental changes in the guinea pig. Histochemistry 1988;90:9-17.

$23 \mathrm{Li} \mathrm{JC}, \mathrm{Mi} \mathrm{KH}$, Zhou JL, et al. The development of colon innervation in trisomy 16 mice and Hirschsprung's disease. World J Gastroenterol 2001:7:16-21.

24 Dzienis-Koronkiewicz E, Debek W, Sulkowska M, et al. Suitability of selected markers for identification of elements of the intestinal nervous system (INS). Eur J Pediatr Surg 2002;12:397-401.
25 Ward SM, Beckett EA, Wang X, et al. Interstitial cells of Cajal mediate cholinergic neurotransmission from enteric motor neurons. J Neurosci 2000;20:1393-403.

26 Wang XY, Sanders KM, Ward SM. Relationship between interstitial cells of Cajal and enteric motor neurons in the murine proximal colon. Cell Tissue Res 2000;302:331-42

27 Ward SM, Burns AJ, Torihashi S, et al. Mutation of the proto-oncogene c-kit blocks development of interstitial cells and electrical rhythmicity in murine intestine. J Physiol (Lond) 1994:480:91-7.

28 Huizinga JD, Thuneberg $L$, Kluppel $M$, et al. W/kit gene required for interstitial cells of Cajal and for intestinal pacemaker activity. Nature 1995;373:347-9.

$29 \mathrm{He} \mathrm{CL}$, Soffer EE, Ferris CD, et al. Loss of interstitial cells of Cajal and inhibitory innervation in insulin-dependent diabetes. Gastroenterology 2001;121:427-34.

30 Isozaki K, Hirota S, Miyagawa J, et al. Deficiency of c-kit+ cells in patients with a myopathic form of chronic idiopathic intestinal pseudo-obstruction. Am J Gastroenterol 1997;92:332-4.

31 Vanderwinden JM, Rumessen JJ. Interstitial cells of Cajal in human colon and in Hirschsprung's disease. Microsc Res Tech 1999;47:344-60.

32 Cortesini C, Pantalone D. Usefulness of colonic motility study in identifying patients at risk for complicated diverticular disease. Dis Colon Rectum 1991;34:339-42.

33 Bassotti G, Battaglia E, de Roberto G, et al. Alterations in colonic motility and relationship to pain in colonic diverticulosis. Clin Gastroenterol Hepatol 2005;3:248-53.

34 Yoneda S, Fukui H, Takaki M. Pacemaker activity from submucosal interstitial cells of Cajal drives high-frequency and low-amplitude circular muscle contractions in the mouse proximal colon. Neurogastroenterol Motil 2004; 16:621-7.

35 Rhl A, Nasser Y, Sharkey KA. Enteric glia. Neurogastroenterol Motil 2004;16(suppl 1):44-9.

36 Takaki M. Gut pacemaker cells: the interstitial cells of Cajal (ICC). J Smooth Muscle Res 2003;39:137-61

37 Huizinga JD, Waterfall WE, Stern HS. Abnormal response to cholinergic stimulation in the circular muscle layer of the human colon in diverticular disease. Scand J Gastroenterol 1999:34:363-8.

38 Golden M, Burleigh DE, Belai A, et al. Smooth muscle cholinergic denervation hypersensitivity in diverticular disease. Lancet 2003;361:1945-51.

39 Streutker CJ, Huizinga JD, Campbell F, et al. Loss of CD1 17 (c-kit)- and CD34-positive ICC and associated CD34-positive fibroblasts defines a subpopulation of chronic intestinal pseudo-obstruction. Am J Surg Pathol 2003:27:228-35.

40 Huizinga JD, Thuneberg L, Vanderwinden JM, et al. Interstitial cells of Cajal as targets for pharmacological intervention in gastrointestinal motor disorders. Trends Pharmacol Sci 1997;18:393-403. 